\title{
Kajian penggunaan daya mesin penggerak KM Coelacanth di Kota Bitung, Provinsi Sulawesi Utara
}

\author{
Study of KM Coelacanth propulsion engine power usage in Bitung City, \\ North Sulawesi Province \\ REVOLS D.CH. PAMIKIRAN* \\ Program Studi Pemanfaatan Sumberdaya Perikanan, Fakultas Perikanan dan Ilmu Kelautan, \\ Universitas Sam Ratulangi, Manado 95115
}

\begin{abstract}
One of important factors affecting the ability of a ship is the usage of its propulsion engine power (HP) and its gained speed $(v(\mathrm{knot}))$ which is suitable for fishing operation needs. This factor is investigated on long-line training ship KM Coelacanth in Bitung City, North Sulawesi. The objectives of this research are to investigate the relationship between engine revolution and propulsion engine power; to investigate the relationship between propulsion engine power and gained speed; to estimate the speed of the boat based on engine power; and to identify the speed category of the ship based on its speed. The results indicated that: (1) the relationship between engine power and speed following mathematical model $v(\mathrm{knot})=\frac{8,528}{1+0,954 e^{-0,01492 \mathrm{HP}}} ;$ (2) the gained speed of the boat based on operated engine revolution and engine propulsion in the field categorizes KM Coelacanth as a boat of normal speed.
\end{abstract}

Keywords: engine, horse power, speed, training ship

\begin{abstract}
ABSTRAK
Salah satu faktor penting yang mempengaruhi kemampuan kapal adalah penggunaan daya mesin penggerak (HP) dan capaian kecepatan kapal $(v(k n o t))$ yang sesuai dengan kebutuhan operasi penangkapan ikan. Faktor ini diteliti pada kapal latih tuna long-line KM Coelacanth di Kota Bitung, Sulawesi Utara. Tujuan dari penelitian ini adalah untuk mengetahui hubungan jumlah putaran mesin dan daya mesin penggerak kapal; hubungan antara daya mesin penggerak dan capaian kecepatan kapal; mengestimasi kecepatan kapal berdasarkan besar daya mesin penggerak kapal; dan mengidentifikasi kategori kapal berdasarkan pada kecepatannya. Hasil penelitian menunjukkan bahwa: (1) hubungan antara daya mesin penggerak dan kecepatan KM Coelacanth mengikuti model persamaan matematik $v($ knot $)=\frac{8,528}{1+0,954 e^{-0,01492 ~ H P}} ;(2)$ capaian kecepatan kapal berdasarkan penggunaan jumlah putaran mesin dan daya mesin penggerak di lapangan mengkategorikan KM Coelacanth sebagai kapal dengan kecepatan normal.
\end{abstract}

Kata-kata kunci: mesin, daya mesin, kecepatan, kapal latih

\section{PENDAHULUAN}

Dalam suatu usaha perikanan atau penangkapan ikan di laut, modal terbesar yang dibutuhkan adalah untuk kapal. Biaya pengadaan kapal adalah lebih besar dibanding biaya pengadaan alat tangkap ataupun alat-alat bantu yang lain. Oleh karena itu, aset ini sangat diharapkan dapat dimanfaatkan atau dipergunakan se-efektif dan seefisien mungkin.

\footnotetext{
*Email: rdolficp@yahoo.com
}

Agar kapal dapat dipergunakan semaksimal mungkin, maka kapal harus memiliki kemampuan yang baik dalam melakukan fungsinya sebagai kapal perikanan. Salah satu faktor yang mempengaruhi kemampuan kapal adalah penggunaan daya (horse power, HP) dari mesin penggerak kapal yang sesuai. Beberapa cara untuk mengestimasi penggunaan daya mesin penggerak kapal dan capaian kecepatan kapal menurut Fyson (1985), Attwod and Pengely (1953), dan Suzuki (1980) adalah: 
1) Berdasarkan pengukuran tahanan kapal secara langsung

2) Berdasarkan nilai koefisien Admiralty (C), dan

3) Berdasarkan kurva hubungan antara $v / \sqrt{\mathrm{L}}$ (speed-length ratio) versus $\mathrm{BHP} / \Delta$, dengan $v$ adalah kecepatan kapal (knot), L adalah panjang kapal (feet), BHP (brake horse power) adalah daya mesin penggerak, dan $\Delta$ adalah adalah displacement tonage kapal atau benaman kapal (ton).

BHP merupakan salah satu indikator daya mesin penggerak selain indikator daya mesin yang lain seperti SHP dan EHP (Fyson, 1985). Displacement tonage adalah berat benaman kapal atau jumlah berat air yang dipindahkan sebagai akibat dari terbenamnya kapal di air. Nilai ini diperoleh dari perkalian volume benaman kapal dengan berat jenis air $(\rho)$ di tempat kapal tersebut terbenam.

Estimasi kecepatan kapal dapat dilakukan berdasarkan kurva hubungan antara $v / \sqrt{\mathrm{L}}$ dengan $\mathrm{BHP} / \Delta$ (Suzuki, 1980), dengan model kurva seperti pada Gbr. 1. Selanjutnya kategori kecepatan kapal berdasarkan speed-length ratio adalah sebagai berikut:

- $v / \sqrt{ } \mathrm{L}=0,8$ : tergolong kecepatan rendah

- $v / \sqrt{ } \mathrm{L}=1,0$ : tergolong kecepatan normal

- $v / \sqrt{\mathrm{L}}=1,2$ :tergolong kecepatan tinggi.

Ayodhyoa (1972) memberikan nilai speed length ratio pada berbagai kapal perikanan. Tabel 1 merupakan kutipan untuk beberapa jenis kapal dengan satuan panjang telah dikonversi dari meter ke feet.

Penyesuaian daya penggerak dapat dilakukan berdasarkan ukuran, kecepatan, dan tujuan dari penggunaan kapal tersebut di lapangan. Lewat suatu kajian dapat diketahui keperluan daya mesin berdasarkan kebutuhan kecepatan kapal (kecepatan rendah, kecepatan normal dan kecepatan tinggi). Berdasarkan hal ini maka dilakukan suatu kajian untuk mengestimasi dan mengevaluasi penggunaan daya mesin penggerak dari salah satu kapal perikanan.

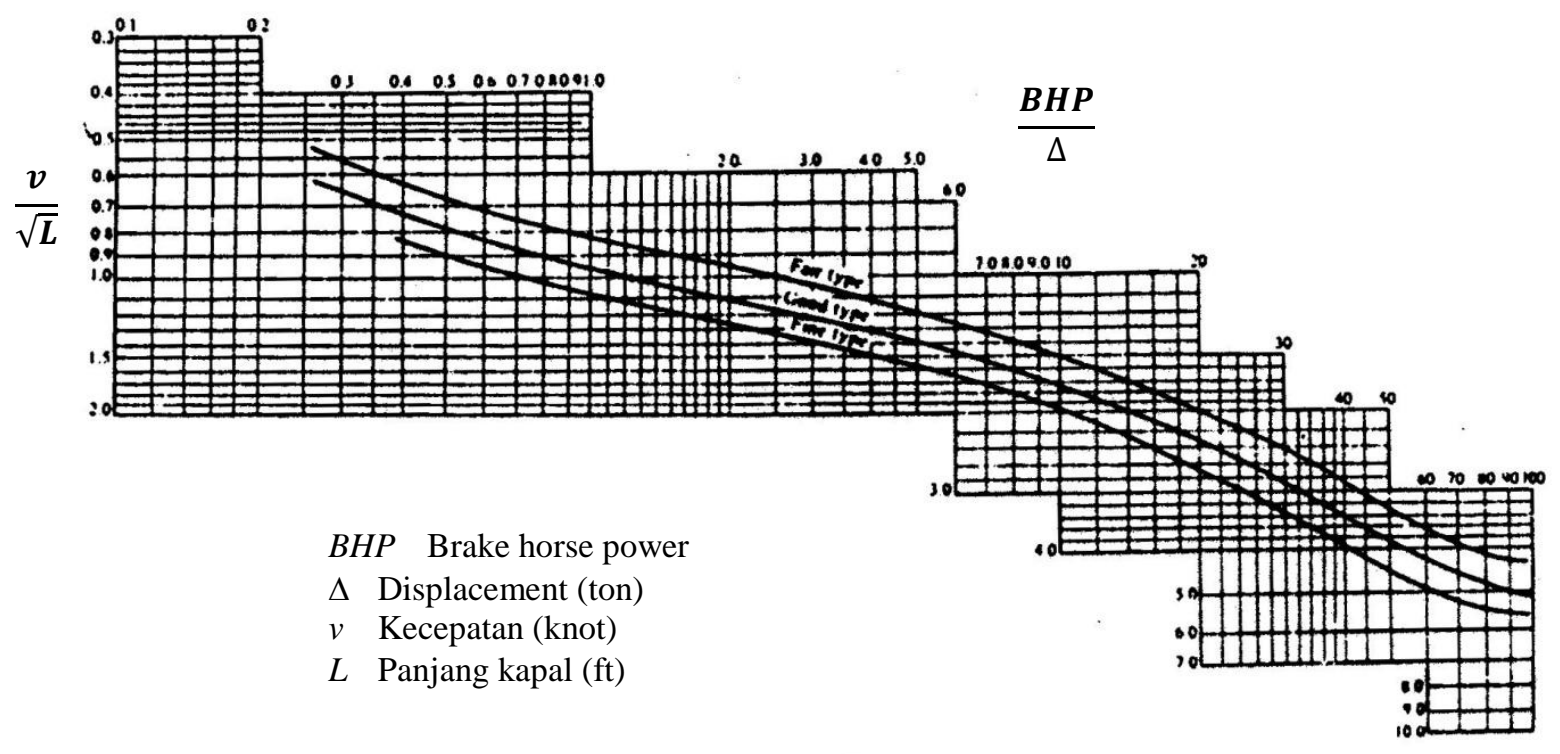

Gambar 1. Kurva estimasi hubungan antara BHP/ $\Delta$ dengan $v \sqrt{ } \mathrm{L}$

Tabel 1. Nilai speed-length ratio beberapa kapal perikanan (Ayodhyoa, 1972)

\begin{tabular}{lccc}
\hline \multicolumn{1}{c}{ Tipe Kapal } & Panjang Kapal (ft) & Kecepatan Kapal (knot) & Speed-Length Ratio \\
\hline Pole and liner & 70,74 & 9,44 & 1,12 \\
Tuna long-liner & 170,56 & 13,78 & 1,06 \\
Trawler & 136,78 & 12,50 & 1,07 \\
\hline
\end{tabular}


Penelitian ini bertujuan untuk (1) mengetahui hubungan jumlah putaran mesin (revolution per minute, rpm) dan daya mesin penggerak; hubungan antara daya mesin penggerak dan capaian kecepatan kapal; dan (2) mengestimasi kecepatan kapal berdasarkan ukuran dan daya mesin penggerak kapal; dan mengidentifikasi kategori kapal berdasarkan kecepatannya. Penelitian ini dapat bermanfaat bagi perencanaan dan evaluasi terhadap efektifitas dan efisinesi penggunaan daya mesin dalam kaitannya dengan capaian kecepatan kapal yang diharapkan.

\section{METODE PENELITIAN}

Penelitian ini dilaksanakan di perairan Aertembaga Kota Bitung, Provinsi Sulawesi Utara pada bulan Juli sampai Agustus 2009. Objek penelitian ini adalah kapal long-line KM Coelacanth. Alat yang digunakan dalam penelitian ini adalah meteran, tacho-meter, kamera, alat tulis-menulis, dan komputer.

Informasi tentang teknis kapal dan daya mesin penggerak yang digunakan diperoleh dari dokumen yang ada di kapal. Berbagai data yang diambil dalam penelitian ini meliputi data spesifikasi kapal yang terdiri dari gambar teknis kapal (lines plan) beserta dengan ukuran-ukuran utama kapal (panjang, lebar, dan dalam), dan draft atau tinggi benaman kapal sebagai dasar perhitungan volume benaman (displacement volume); dan data mesin penggerak yang meliputi spesifikasi mesin dan jumlah putaran mesin yang diukur dengan menggunakan tacho-meter.

Analisis data yang dilakukan dalam penelitian ini meliputi

1. Perhitungan volume benaman kapal dengan menggunakan aturan Simpson I (Attwod and Pengely, 1953).

2. Analisis daya mesin penggerak kapal berdasarkan pada kurva standar hubungan antara jumlah putaran mesin per menit dan daya mesin yang dihasilkan dalam satuan kilowatt $(\mathrm{kW})$, dan mengkonversinya ke dalam satuan HP berdasarkan Ohanian (1994).

3. Analisis speed-length ratio (Suzuki, 1980).

4. Analisis hubungan dan pemetaan kurva BHP/D dan $v / \sqrt{ } \mathrm{L}$ berdasarkan data daya mesin penggerak, benaman kapal (displacement ton), dan ukuran panjang kapal (L). Kecepatan kapal diestimasi berdasarkan ketiga data di atas dengan menggunakan kurva standar (Gambar
1). Garis kurva yang digunakan adalah garis fair type (berada di bagian tengah), sesuai bentuk badan kapal yang diteliti.

\section{HASIL DAN PEMBAHASAN}

KM Coelacanth adalah tipe kapal long-line dengan spesifikasi: panjang (LOA) $17 \mathrm{~m}$, panjang garis air (LWL) 14,2 m, lebar (B) 4,10 m, dalam (D) 2,10 $\mathrm{m}$, dan Gross Tonnage 25 GT. Lines plan di tampilkan pada Gbr. 2. Kapal ini menggunakan mesin penggerak utama merek Yanmar tipe $6 \mathrm{CH}-$ HTE3 (Gbr. 3) dengan jumlah putaran mesin maximum $2550 \mathrm{rpm}$.

\section{Hubungan antara jumlah putaran mesin dan daya mesin}

Tabel 2 menyajikan nilai dari rpm dan daya mesin dalam satuan kilowatt $(\mathrm{kW})$ dan HP. Nilai ini diperoleh dari spesifikasi mesin kapal yang digunakan dan melalui konversi daya dari $\mathrm{kW}$ ke HP.

Tabel 2. Putaran dan daya mesin KM Coelacanth

\begin{tabular}{crr}
\hline Putaran Mesin & \multicolumn{2}{c}{ Daya Mesin } \\
\cline { 2 - 3 }$(\mathrm{rpm})$ & $\mathrm{kW}$ & $\mathrm{HP}$ \\
\hline 1400 & 53 & 71 \\
1600 & 75 & 100 \\
1800 & 97 & 130 \\
2000 & 110 & 147 \\
2200 & 117 & 158 \\
2400 & 123 & 165 \\
\hline
\end{tabular}

Hasil analisis hubungan jumlah putaran mesin dan daya mesin yang dihasilkan adalah sebagai berikut:

$$
H P=\frac{169,5}{\left(1+e^{6,249-0,00394(\mathrm{rpm})}\right)^{\frac{1}{1,280}}}
$$

Pemetaan dari hubungan antara jumlah putaran mesin dan daya mesin ditampilkan pada Gbr. 4.

Berdasarkan pemetaan dan hubungan pada gambar dapat dijelaskan bahwa pada nilai jumlah putaran mesin rendah masih terjadi pertambahan nilai daya mesin yang berarti, tetapi pada rpm yang yang mendekati nilai maksimum pertambahan daya mesin sudah mulai berkurang. 

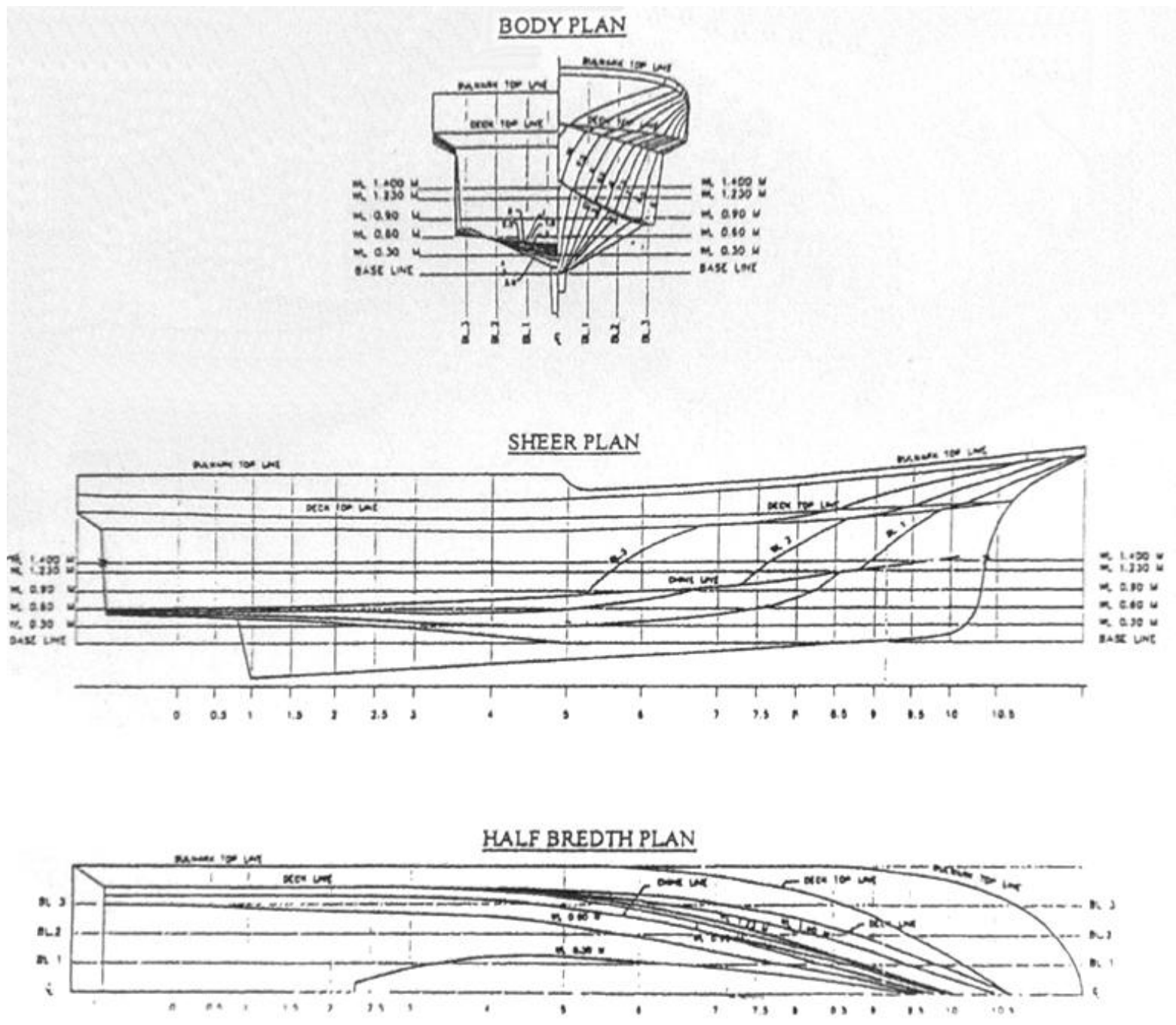

Gambar 2. Lines plan KM Coelacanth
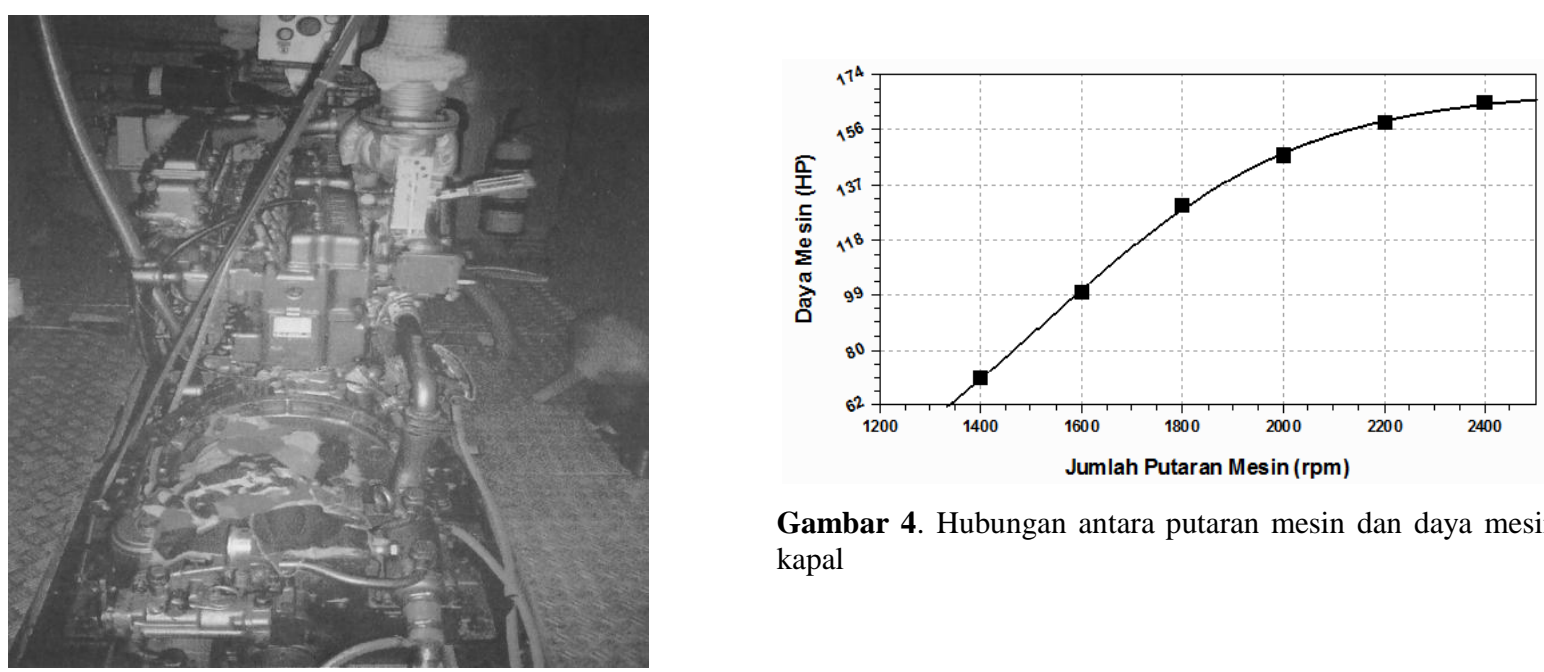

Gambar 4. Hubungan antara putaran mesin dan daya mesin kapal

Gambar 3. Mesin penggerak merek Yanmar 


\section{Hubungan daya mesin dan kecepatan kapal}

Daya mesin penggerak kapal dan nilai estimasi kecepatan kapal dengan menggunakan kurva standar (Gbr. 1) disajikan pada Tabel 3.

Tabel 3. Daya mesin penggerak kapal dan nilai estimasi kecepatan kapal

\begin{tabular}{ccccccc}
\hline $\begin{array}{c}\text { Daya Mesin } \\
(\mathrm{HP})\end{array}$ & 71 & 100 & 130 & 147 & 158 & 165 \\
\hline $\begin{array}{c}\text { Kecepatan } \\
\text { Kapal (knot) }\end{array}$ & 6,41 & 7,02 & 7,50 & 7,71 & 7,83 & 7,87 \\
\hline
\end{tabular}

Dari analisis hubungan antara daya mesin penggerak kapal dan kecepatan kapal diperoleh hubungan logistic dengan model matematis sebagai berikut:

$$
v=\frac{8,528}{1+0,954 e^{-0,01492 H P}}
$$

Pemetaan diagram sebaran dan garis peramalan hubungan antara daya mesin dan kecepatan disajikan pada Gbr. 5.

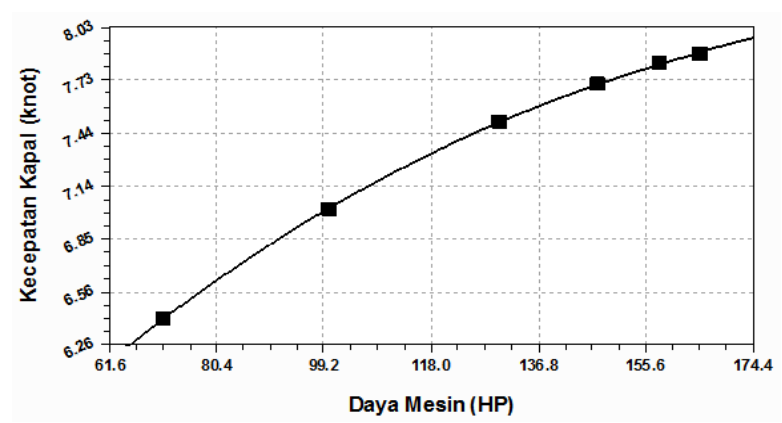

Gambar 5. Hubungan antara daya mesin dan kecepatan kapal

Jumlah putaran mesin dinas kapal adalah 1000 $2000 \mathrm{rpm}$ dengan estimasi interval daya mesin adalah 71-165 HP, dan estimasi interval capaian kecepatan kapal adalah 6,41-7,87 knot. Berdasarkan pada speed-length ratio, kecepatan kapal unutk kategori kecepatan rendah, normal, dan tinggi secara berturut-turut adalah 5,45, 6,82, dan 8,18 knot. Walaupun speed-length ratio sudah sesuai dengan yang dikemukakan dalam Ayodhyoa (1972), penggunaan nilai tertinggi putaran mesin yang biasa digunakan di lapangan belum dapat mencapai kategori kecepatan tinggi kapal. Putaran mesin demikian hanya mampu memberikan kontribusi dicapainya kategori kecepatan normal kapal yang diteliti. Dengan kata lain, penggunaan jumlah putaran mesin dan daya penggerak untuk mencapai kecepatan tinggi kapal belum terpenuhi. Berdasarkan pada hubungan antara jumlah putaran mesin dan daya mesin yang dihasilkan; dan hubungan antara daya mesin dan kecepatan kapal, maka agak sulit untuk menambah kecepatan kapal. Kesulitan ini karena penambahan putaran mesin tidak lagi memberikan pertambahan yang berarti terhadap daya mesin, demikian juga dengan kontribusi pertambahan daya mesin terhadap kecepatan kapal. Hal ini merupakan masalah dalam penggunaan kapal di lapangan karena kapal hanya dapat mencapai kecepatan normal serta tidak adanya ekstra daya penggerak kapal dalam menghadapi situasi perairan yang tidak diharapkan seperti arus dan gelombang.

\section{KESIMPULAN}

Hubungan antara daya mesin penggerak dan kecepatan kapal long-line KM Coelacanth di Kota Bitung, Propinsi Sulawesi Utara, mengikuti model persamaan matematik:

$$
v=\frac{8,528}{1+0,954 e^{-0,01492 H P}}
$$

Capaian kecepatan kapal berdasarkan jumlah putaran mesin dan daya mesin penggerak di lapangan mengkategorikan KM Coelacanth sebagai kapal dengan kategori kecepatan normal.

\section{DAFTAR PUSTAKA}

Ayodhyoa, A.U. 1972. Fishing Boat. Fakultas Perikanan, Institut Pertanian Bogor.

Attwood, L.D. dan S.H. Pengely. 1953. Theoretical Naval Architecture. Longmans, Green and Co.Ltd., London.

Fyson, J. (Editor). 1985. Design of Small Fishing Vessels. FAO. Fishing News Books Ltd. Farnham-Surrey-England.

Ohanian, C.H. 1994. Principles of Physics. W.W. Norton and Company, New York.

Sudjana. 1980. Desain dan Analisis Eksperimen. Penerbit Tarsito, Bandung.

Suzuki, O. 1980. Handbook for Scientists and Technologist. Training Departement Southeast Asian Fisheries Development Center, Thailand. 